\title{
Resistance testing of Salmonella spp. bacteria isolated from samples derived from poultry on antimicrobial drugs
}

\begin{abstract}
In accordance with the Ordinance on establishing measures for the early detection, diagnosis, prevention of spreading, suppression and eradication of poultry infection by certain Salmonella serotypes, antimicrobial agents are also applied in controlling salmonellas is of poultry, and the very treatment may lead to development of resistance to different drugs.

The aim of this study was to determine the antimicrobial resistance of isolates, isolated from material originating from poultry farms during the one-year period (2014) in the territory of Nis and South Moravian epizootiological area. For the isolation and identification of causers, the standard microbiological methods according to EN ISO 6579: 2008 Annex D were used. Antimicrobial resistance is tested on 72 isolates of Salmonella spp. Examination of antimicrobial resistance was carried out by the disk diffusion method on Mueller-Hinton agar and interpreted according to the CLSI standard. The paper used thirteen types of antibiotic discs (Bioanalyse): enrofloxacin, norfloxacin, florfenicol, ceftiofur, amoxicillin, colistin, erythromycin, gentamicin, neomycin, kanamycin, flumequine, lincomicin/spectinomicin and sulfamethoxazole/ trimethoprim.

The results indicate the existence of a high percentage of resistance to some antimicrobial drugs. The greatest observed resistance was to erythromycin $(68 \%$ at strain $S$. Enteritidis and $67 \%$ at $S$. Infantis), neomycin (61\% at strain S. Enteritidis and $33 \%$ at S. Infantis), flumequine(32\% at strain S. Enteritidis and 53\% at S. Infantis), strains of S. Enteritidis showed a great resistance to kanamycin and sulfapreparations(23\%) and colistin(20\%), while the strains of $S$. Infantis were resistant in a large percentage to amoxicillin(47\%) and colistin(33\%). There is slightly less resistance to other antibacterial drugs, and only a few isolates were resistant to quinolones and gentamycin. The emergence of resistant strains of Salmonella can result in the possibility of treating animals and humans and therefore a more rigorous implementation of measures for the suppression of salmonellosis in animals is required.
\end{abstract}

Keywords: antibiotics, antimicrobial resistance, Salmonella spp., poultry
Volume 3 Issue 2 - 2016

\author{
Marija Manic, Sonja Nikolic,Vladimir \\ Marjanovic, Sladjana Antanasijevic, Zoran \\ Raicevic, Milos Petrovic \\ Veterinary specialist institute "Nis" Nis, Serbia
}

Correspondence: Marija Manic, Veterinary specialist institute “Nis”, Milke Protić bb, Nis, Serbia, Tel +38I 640604 965,

Email marijavsinis@gmail.com

Received: February 19, 2016 | Published: March 08, 2016

\section{Introduction}

Salmonellosis is a zoonosis, an infectious disease of humans and animals caused by bacteria of the genus Salmonella. The genus Salmonella (S.) is divided into two species: Salmonella enterica and Salmonella bongori. More than 99\% of known serotypes of Salmonella and all the most important serotypes that are pathogenic for humans belong to the species of Salmonella enterica. Certain serotypes are "host-specific", have a small host range and can cause serious systemic infections ( $S$. Gallinarum in poultry, S. Typhi in humans or S. Abortus-ovis in sheep). The second group includes "host restricted" serotypes, they are adapted to a wide host range (S. Dublin causes serious disease of cattle, but it may also infect humans). There is a third group named "generalist", which includes the ubiquitous serotypes with a broad host range ( $S$. Enteritidis, $S$. Typhimurium, S. Infantis, S. Hadar). Ubiquitous serotypes rarely cause systemic disease in animals and humans, but they are able to colonize the gastrointestinal tract of many species of hosts. Due to frequent colonization and fecal excretion of animals bred for human consumption, ubiquitous serotypes enter the food chain and can cause salmonellasis cases in humans. ${ }^{1}$
According to the World Health Organization in 1995 in 191 member countries, the three most common serotypes of Salmonella isolated from humans were $S$. Enteritidis, S. Typhimurium and $S$. Typhi (76.1\% of all registered cases). In Europe, where there are no endemic infections with $S$. Typhi, the most common serotypes were S. Enteritidis (64.5\%), S. Typhimurium, S. Infantis, S. Virchow and S. Newport. ${ }^{2}$ People can become infected with Salmonella by direct contact with animals or by the fecal-oral route. However, the most important and most common route of transmission of salmonellosis is through contaminated food of animal origin. Infection of humans by serotypes $S$. Enteritidis is frequently associated with the consumption of chicken eggs and poultry meat. In recent years, the worldwide decline in the number of cases of Salmonella infections was observed in comparison to the previous period, likely due to increased awareness and implementation of programs for the control of Salmonella on farms and in the production process, ${ }^{3}$ but according to some authors the drop in the number of patients is a temporary fluctuation. ${ }^{4}$

Salmonellosis of poultry is a particularly significant problem in public health. The mere presence of Salmonella in poultry flocks and the emergence of salmonellosis caused great economic losses 
in poultry production. Direct damage can occur at every stage of production. Infections of adult poultry often pass asymptomatically; however, at this stage production costs significantly increase due to measures taken to prevent the spread on the progeny and the people. While other serotypes of Salmonella can colonize the gastrointestinal organs of livestock, only S. Typhimurium and S. Enteritidis can colonize the reproductive organs and thus contaminate eggs in the course of formation. Additionally, $S$. Enteritidis is able to survive in the egg after spawning, can be found in the egg white and yolk, but is more common in the egg white.

Given the widespread occurrence of Salmonella in nature, the customary treatment of animals is by antimicrobial agents. As a consequence resistance to different drugs develops. Resistance interferes with the treatment of people, but it also creates a cumulative environmental problem. During the contact of resistant salmonella and saprophytic bacteria in the gastrointestinal tract, the resistance genes from Salmonella can be transferred into the genome of saprophytic bacteria sensitive to antibiotics through horizontal plasmid transportation. In this way, saprophytic and/or opportunistic bacteria acquire point mutations in specific genes of the genome of its own and become resistant. ${ }^{6}$ Until recently it was thought that Salmonella are "antibiotic foreseeable" bacteria, that are always sensitive to all antibiotics and that do not develop resistance. The first cases of Salmonella resistant to antibiotics have emerged in the mid-eighties in strains of $S$. Enteritidis and S. Typhimurium. Initially the resistance existed only to ampicillin and tetracycline. In the midnineties of the last century appeared a multiresistant strain of $S$. Typhimurium (DT 104), which was resistant to ampicillin, fluorinated quinolones, streptomycin, sulfonamides, tetracyclines, trimethoprim, spectinomicin and disinfectants. This strain in the Scandinavian countries caused great economic losses due to mortality on swine farms, and spread on the other animal species and humans, causing high mortality. ${ }^{78}$

In recent years, the emergence and spread of antibiotic resistant strains of zoonotic bacteria pose a serious public health problem. Everything is the result of a long-term antibiotic therapy, which leads to the emergence of antimicrobial resistance to one or more antibiotics (multiresistance). It has been shown that the resistance genes are located on plasmids, that these genes are often grouped into integrons and that the transfer of resistance to progeny of bacteria is very common. ${ }^{9,10}$

In Serbia, in the ten-year period from 2004 to 2013 the declining trend of the incidence of antimicrobial resistance for S. Enteritidis (7\%) and S. Hadar was observed. Testing isolates of S. Typhimurium registered the significant occurrence of resistance, especially multiresistance. It was found about $30 \%$ of resistant isolates with distinct heterogeneity of phenotypes and high incidence of multiresistant isolates $(83 \%)$. Also, the resistance in the strain of $S$. Infantis ${ }^{11}$ is getting more common. The European Union's Council Directive 2003/99/EC prescribes mandatory monitoring of Salmonella resistance as well as other zoonotic organisms. Whereas the influence of pathogenic effects of Salmonella on human population is of great importance, the aim of this study was to determine the antimicrobial resistance of isolates, isolated from materials originating from poultry during the one-year period, in 2014, on the territory of Nis and South Moravian epizootiological areas.

\section{Materials and methods}

As a material for testing, isolates of Salmonella spp. collected in
2014 from material originating from poultry farms (samples of faeces, carcasses of poultry, washers and samples from the environment) were used. Materials are reviewed in accordance with the Regulations on establishing measures for the early detection, diagnosis, prevention of spreading, suppression and eradication of infections of poultry by certain Salmonella serotypes ${ }^{12}$ and on the basis of contractual cooperation with the owners, in the course of ordinary and extraordinary control as well as during an inspection. In 2014 a total of 2113 samples were examined for the presence of Salmonella.

For the isolation and identification of causers, the standard microbiological methods according to EN ISO 6579:2008 Annex D were used. The $25 \mathrm{~g}$ of samples each were poured with $225 \mathrm{ml}$ of BPW (Buffered Peptone Water, HiMedia Laboratories, India) and incubated for $18-22 \mathrm{~h}$ at a temperature of $37^{\circ} \mathrm{C}$. After incubation, $0.1 \mathrm{ml}$ was sieved on MSRV (Modified semi-solid Rappaport Vassiliadis, HiMedia Laboratories, India) agar and incubated for $24 \mathrm{~h}$ at a temperature of $41.5^{\circ} \mathrm{C}$, and $1 \mathrm{ml}$ of BPW is sieved in MKTTn (Muller-Kauffmann-Tetrathionate Broth Novobiocin-Muler Kaufman tetrathionate broth, Biokar Diagnostics, France) and incubated during $24 \mathrm{~h}$ at a temperature of $37^{\circ} \mathrm{C}$. After the expiry of incubation, the broth cultures were re-sieved on XLD (Xylose Lysine deoxycholate Agar, HiMedia Laboratories, India), and BGA (Brilliant Green Agar, HiMedia Laboratories, India), and incubated for $24 \mathrm{~h}$ at a temperature of $37^{\circ} \mathrm{C}$. Obtained isolates were purified and biochemically and serologically tested for Salmonella species affiliation. We identified 72 isolates of Salmonella spp. and all isolates were tested for antimicrobial resistance.

Investigation of antimicrobial resistance was carried out by the disk diffusion method on Mueller-Hinton agar (HiMedia Laboratories, India) and interpreted according to the CLSI standard - Clinical and Laboratory Standards Institute documents M100-S22. ${ }^{13}$ Thirteen types of antibiotic discs were used: enrofloxacin (ENR-5 $\mu \mathrm{g}$ ), norfloxacin (NOR-10 $\mu$ g), florfenicol (FFC-30 $\mu \mathrm{g}$ ), ceftiofur (FUR-

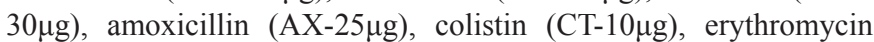
$(\mathrm{E}-15 \mu \mathrm{g})$, gentamycin $(\mathrm{GN}-10 \mu \mathrm{g})$, neomycin $(\mathrm{N}-30 \mu \mathrm{g})$, kanamycin $(\mathrm{K}-30 \mu \mathrm{g})$, flumequine (FLM-30 $\mu \mathrm{g}$ ), lincomycin /spectinomycin

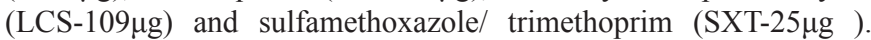
For quality control, we used the reference cultures of Salmonella enteritidis $\mathrm{ATCC}^{\circledR} 13076^{\mathrm{TM}}$.

\section{Results and discussion}

In 2014, on a total of 2113 samples originating from poultry were examined (samples of faeces, carcasses of poultry, washers and samples from the environment), of which $72(3.40 \%)$ were positive for the presence of Salmonella. Table 1 shows that the most frequently isolated Salmonella serotypes were $S$. Enteritidis 44 samples(61.11\%), S. Infantis 15 samples (20.83\%) and S. Typhimurium 7 samples $(9.72 \%)$. Much less present were other serotypes of Salmonella-S. Montevideo, S. Newport and S. Paratyphi A.

By testing sensitivity of isolated strains of $S$. Enteritidis to antimicrobial drugs, resistance to fluorinated quinolones was less than $5 \%$, or only two strains showed resistance to enrofloxacin and norfloxacin. The high prevalence of resistance is found to erythromycin $(68 \%)$, neomycin $(61 \%)$, flumequine $(32 \%)$, kanamycin $(23 \%)$, sulfamethoxazole/trimethoprim $(23 \%)$ and colistin $(20 \%)$. Other results related to resistance to antibiotics in strains of $S$. Enteritidis in comparison to the total number of examined isolates of S. Enteritidis are shown in Figure 1. 
$S$. Infantis shows good sensitivity to fluorinated quinolones, cephalosporins, lincomycin/spectinomycin and sulfa preparations, while the great resistance occurs to erythromycin (67\%), flumequin
(53\%), amoxicillin (47\%), neomycin and colistin (by 33\%) (Table 2). The results of presence of antibiotic resistance in strains of $S$. Infantis are shown in Figure 2.

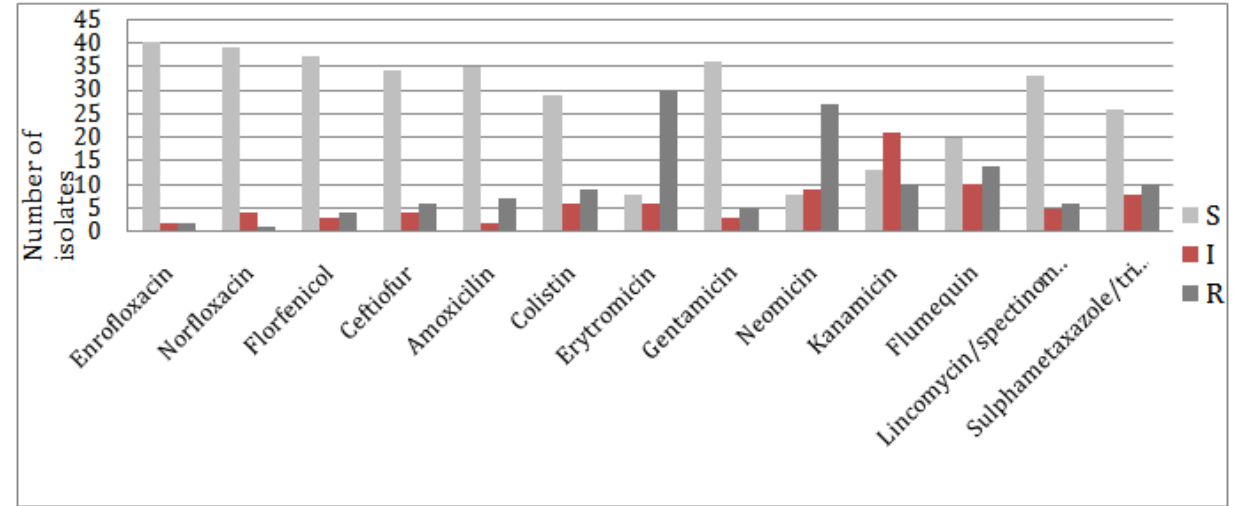

Figure I Resistance in S. Enteritidis strains to antibiotics compared to the total number of examined isolates S. Enteritidis.

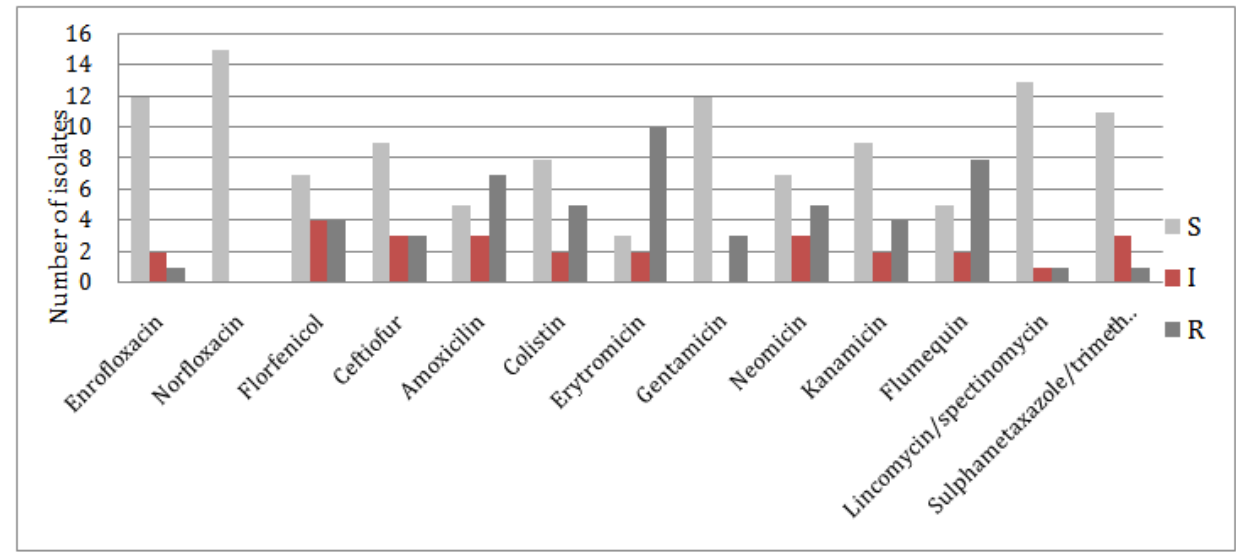

Figure 2 Resistance in S. Infantis strains to antibiotics compared to the total number of examined isolates S. Infantis.

Table I Resistance in S. Enteritidis strains to antibiotics compared to the total number of examined isolates $S$. Enteritidis

\begin{tabular}{llll}
\hline & S & I & R \\
\hline Enrofloxacin & 40 & 2 & 2 \\
Norfloxacin & 39 & 4 & 1 \\
Florfenicol & 37 & 3 & 4 \\
Ceftiofur & 34 & 4 & 6 \\
Amoxicilin & 35 & 2 & 7 \\
Colistin & 29 & 6 & 9 \\
Erytromicin & 8 & 6 & 30 \\
Gentamicin & 36 & 3 & 5 \\
Neomicin & 8 & 9 & 27 \\
Kanamicin & 13 & 21 & 10 \\
Flumequin & 20 & 10 & 14 \\
Lincomycin/Spectinomycin & 33 & 5 & 6 \\
Sulphametaxazole/Trimethoprim & 26 & 8 & 10 \\
\hline
\end{tabular}

Table 2 Resistance in S. Infantis strains to antibiotics compared to the total number of examined isolates $S$. Infantis

\begin{tabular}{llll}
\hline & S & I & R \\
\hline Enrofloxacin & 12 & 2 & I \\
Norfloxacin & 15 & 0 & 0 \\
Florfenicol & 7 & 4 & 4 \\
Ceftiofur & 9 & 3 & 3 \\
Amoxicilin & 5 & 3 & 7 \\
Colistin & 8 & 2 & 5 \\
Erytromicin & 3 & 2 & 10 \\
Gentamicin & 12 & 0 & 3 \\
Neomicin & 7 & 3 & 5 \\
Kanamicin & 9 & 2 & 4 \\
Flumequin & 5 & 2 & 8 \\
Lincomycin/Spectinomycin & 13 & 1 & 1 \\
Sulphametaxazole/Trimethoprim & 11 & 3 & 1 \\
\hline
\end{tabular}


The number of Salmonella isolated from the strain of $S$ Typhimurium was small to assess antimicrobial resistance. By testing sensitivity of isolated strains of S. Typhimurium to antibacterial drugs, a complete sensitivity to fluorinated quinolones and gentamicin and small resistance of aminoglycoside antibiotics, lincomycin/ spectinomycin and sulfa preparations were found. The highest rates of resistance were found in erythromycin, flumequine, colistin and cephalosporins.

The study of resistance to antimicrobial agents in two isolates of $S$. Newport, and in three isolates of S. Montevideo showed resistance only to amoxicillin and flumequine. Salmonella Paratyphi $A$ is only to be resistant to amoxicillin. When we compare our data with data from the literature, it can be seen that in other regions of our country and in other countries $S$. Enteritidis is most frequently isolated Salmonella in both animals and humans. ${ }^{11,14,15}$ Salmonella Infantis is in recent years increasingly isolated in animals and in human medicine. ${ }^{11,16}$

The most frequently isolated strain in poultry flocks, S. Enteritidis, showed considerable resistance to some antibiotics. It is the result of a long-term use of certain antibiotics in poultry. For S. Enteritidis there is great resistance to the following antibiotics: erythromycin, neomycin, flumequine, kanamycin and colistin. If we compare our results with the results of other authors in the past, we can conclude that resistance among our isolates is much higher especially to erythromycin, flumequin, colistin and sulfa preparations. ${ }^{17,18}$ Resistance to fluorinated quinolones is small despite the widespread use in poultry, particularly resistance to enrofloxacin. Enrofloxacin is not an effective drug in the treatment of salmonellosis of birds because after stopping the therapy Salmonella colonize the intestinal tract again. This medicine was withdrawn from use in poultry in the United States because its use can develop resistance in Campylobacter species. ${ }^{8}$ For the emergence of resistance to quinolones in S. Enteritidis, gene mutation girA is responsible. The same mutation leads to the emergence of multiresistant strains. According to research conducted in our country multiresistant Salmonella strains are present in poultry, and the findings of some authors point to the need for the introduction of the laboratory practice of adequate system of molecular standardization of strains and monitoring of resistance, particularly resistance to quinolones in Salmonella. ${ }^{19,20}$

Monitoring of resistance in S. Infantis is very important due to the frequent occurrence of this serotype that is mainly derived from poultry. According to research Velhner et al. ${ }^{21}$ PFGE analysis showed that in Serbia $S$. Infantis isolates have similar genetic profile indicating a clonal spread of resistance. ${ }^{21}$

The problem with resistance in the strain of $S$. Typhimurium is serious because of the emergence of multiresistant strains of $S$. Typhimurium DT104, DT204, DT193 etc. which give rise to serious alimentary toxicoinfections and large losses in livestock. ${ }^{8,18}$

The growing phenomenon of resistance to antimicrobial medicines and particularly reduced sensitivity to cephalosporins and fluoroquinolones narrows drugs choice for effective antibiotic therapy and leads to problems with the treatment of severe forms of salmonellosis in humans. Resistance not only interferes with the treatment of humans and animals, but also creates a cumulative environmental problem. In the control of salmonellosis, what is of great importance is risk assessment and monitoring of different sources of infection and ways of its dissemination, system control, good hygiene practices in animal breeding and food production as well as vaccination of animals are necessary. There is a real need for a global initiative and establishing control over potentially dangerous bacterial strains and more rigorous implementation of measures to combat them in animals. Control measures include disinfection of buildings and equipment, rodent control, vaccination, treatment, and laboratory testing. Based on the research of some authors, ${ }^{19,20}$ there is a need for the application of molecular methods in antibiotic resistant strains in order to reveal the mechanisms of resistance occurrence and origin of strains (epizootiological and possibly epidemiological) or the origin of their resistant phenotypic traits.

\section{Conclusion}

Based on our results we can conclude that salmonella strains isolated from samples originating from poultry show the existence of resistance to certain antimicrobial drugs. By testing sensitivity of isolated $S$. Enteritidis strains to a panel of thirteen antibiotics, a high frequency of resistant isolates and multiply resistant isolates was established. The most common are resistances to erythromycin (68\%), neomycin $(61 \%)$, flumequine $(32 \%)$, sulfapreparations, kanamycin $(23 \%)$ and colistin $(20 \%)$. Similar results are found with isolates $S$. Infantis, the largest resistance was observed to erythromycin (67\%), flumequine (53\%), amoxicillin (47\%), neomycin and colistin (33\%). For other antibacterial drugs there is much less resistance. Resistance of isolated Salmonella from our region to fluoroquinolones is low (less than 5\%) which is good as the fluoroquinolones are often used in human therapy.

\section{Acknowledgements}

None.

\section{Conflict of interest}

Author declares that there is no conflict of interest.

\section{References}

1. Van Hoorebeke S, Van Immerseel F, Haesebrouck F, et al. The Influence of the Housing System on Salmonella Infections in Laying Hens: A Review. Zoonoses Public Health. 2011;58(5):304-311.

2. Annual Epidemiological Report on Communicable Diseases in Europe 2010. Stockholm: ECDC. ECDC-European Centre for Disease Prevention and Control. 2010.

3. EFSA and ECDC-European Food Safety Authority, European Centre for Disease Prevention and Control. The European Union Summary Report on Trends and Sources of Zoonoses, Zoonotic Agents and Food-borne Outbreaks in 2009. EFSA Journal. 2011;9(3):2090.

4. Velge P, Cloeckaert A, Barrow P. Emergence of Salmonella epidemics: The problems related to Salmonella enterica serotype Enteritidis and multiple antibiotic resistance in other major serotypes. Vet Res. 2005;36(3):267-288.

5. Clavijo RI, Loui C, Andersen GL, et al. Identification of Genes Associated with Survival of Salmonella enterica Serovar Enteritidis in Chicken Egg Albumen. Appl Environ Microbiol. 2006;72(2):1055-1064.

6. Carattolli A. Plasmid-Mediated Antimicrobial Resistance in Salmonella enterica. Curr Issues Mol Biol. s(4):113-122.

7. Mišić D. Rezistencija na antibiotike kod bakterija izolovanih od životinja u Republici Srbiji. Savetovanje veterinara Srbije, Zlatibor. 2012;23(13-16):67-82.

8. Velhner M, Potkonjak D, Stojanovic D, et al. Antimicrobial resistance of Salmonella and control measures in poultry industry. Veterinarski Glasnik. 2013;67(1-2):87-96. 
9. Echeita MA, Aladuena A, Cruchaga S, et al. Emergence and spread of an atypical Salmonella enterica subsp enterica serotype 4,5,12 : i :- Strain in Spain. J Clin Microbiol. 1999;37(10):3425-3425.

10. Guerra B, Laconcha I, Soto SM, et al. Molecular characterisation of emergent multiresistant Salmonella enterica serotype [4,5,12:i: ] organisms causing human salmonellas. FEMS Microbiol Lett. 2000;190(2):341-347.

11. Galić-Živanić Nataša, Pavlović Ljiljana, Grego Edita. Prevalencija antimikrobne rezistencije kod humanih netifoidnih izolata Salmonella enterica u Srbiji (kratak sadržaj). X kongres mikrobiologa Srbije Mikromed. 2015;43-44.

12. Pravilnik o utvrđivanju mera za rano otkrivanje, dijagnostiku, sprečavanje širenja, suzbijanje i iskorenjivanje infekcija živine određenim serotipovima salmonella («Sl. glasnik RS”, br. 7/10)

13. Performance Standards for Antimicrobial Susceptibility Testing; Twenty- Second Informational Supplement. Wayne, PA: Clinical and Laboratory Standards Institute document M100-S22. CLSI-Clinical and Laboratory Standards Institute. 2012.

14. Stojanov I, Kapetanov M, Prodanov-Radulović J, et al. The resistency of Salmonella serovar. enteritidis/infantins isolated in poultry against naldixic acid. Biotechnology in Animal Husbandry. 2011;27(3):751-758.
15. Carraminana JJ, Rota C, Agustin I, et al. High prevalence of multiple resistance to antibiotics in Salmonella serovars isolated from a poultry slaughterhouse in Spain. Veterinary Microbiology. 2004;104(1-2):133-139.

16. Ohad Gal-Mor, Lea Valinsky, Miriam Weinberger, et al. MultidrugResistant Salmonella enterica Serovar Infantis. Israel. Emerging Infectious Diseases. 2010;16(11):1754-1757.

17. Stošić Zorica, Mitrić M, Kiškarolj F, et al. Ispitivanje osetljivosti sojeva Salmonella vrsta poreklom od živine sa različitih epizootioloških područja na antibiotike. Vet glasnik. 2006;60(1-2):89-98.

18. Mišić D, Stošić Zorica, Kiškarolj F, et al. Ispitivanje multirezistencije E. coli i salmonella koje potiču od domaćih životinja na antibiotike i hemioterapeutike. Vet glasnik. 2006;60(1-2):21-31.

19. Kozoderović G, Velhner M, Jelešić Z, et al. Molecular typing and antimicrobial resistance of Salmonella Enteritidis isolated from poultry, food and humans in Serbia. Folia Microbiol. 2011;56(1):66-71.

20. Velhner M, Stojanović D, Stefan-Mikić S, et al. Evidence of gyrA mutations in nalidixic acid resistant Salmonella enterica serotype enteritidis. Bulgarian Journal of Veterinary Medicine. 2014;17(1):25-31.

21. Velhner M, Kozoderović G, Grego E, et al. Clonal Spread of Salmonella enteric Serovar Infantis in Serbia: Acquisition of Mutations in the Topoisomerase Genes gyrA and parC Leads to Increased Resistance to Fluoroquinolones. Zoonoses and Public Health. 2013;61(5):364-370. 